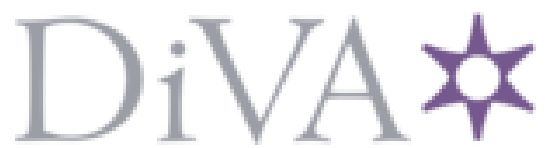

http://www.diva-portal.org

\title{
Postprint
}

This is the accepted version of a paper published in International Journal of Production Economics. This paper has been peer-reviewed but does not include the final publisher proofcorrections or journal pagination.

Citation for the original published paper (version of record):

Fundin, A., Bergquist, B., Eriksson, H., Gremyr, I. (2018)

Challenges and propositions for research in quality management

International Journal of Production Economics, 199: 125-137

https://doi.org/10.1016/j.ijpe.2018.02.020

Access to the published version may require subscription.

N.B. When citing this work, cite the original published paper.

Permanent link to this version:

http://urn.kb.se/resolve?urn=urn:nbn:se:mdh:diva-38848 


\section{Challenges and propositions for research in quality management}

Anders Fundin ${ }^{a}$, Bjarne Bergquist $^{\mathrm{b}}$, Henrik Eriksson ${ }^{\mathrm{c}}$, and Ida Gremyr ${ }^{\mathrm{c}}$

aSchool of Innovation, Design and Engineering, Mälardalen University, Box 325, 63105

Eskilstuna, Sweden, Email: anders.fundin@mdh.se, Phone: +46739607205

bDepartment of Business Administration and Social Sciences, Luleå University of Technology, 97187 Luleå, Sweden

'Department of Technology Management and Economics, Chalmers University of Technology, 41296 Gothenburg, Sweden

*Author of correspondence 


\begin{abstract}
From its inception, the field of quality management $(\mathrm{QM})$ has been characterised by practicedriven development. Although QM has reached maturity as a field of research based on empirical enquiry, its practitioners still struggle to adapt QM implementations to reap their benefits. This study aims to identify their challenges to better understand how contemporary QM research addresses them. We propose approaches to bridge the potential relevance gaps between research and practice. A Delphi study of QM practitioners in Swedish private and public organisations, several of which operate globally, generated 49 challenges. An exploratory factor analysis was performed to cluster these challenges into themes, and the literature was reviewed to investigate how each theme has been addressed in QM research. The empirical investigation identified three themes related to future QM challengesorganisations' adaptability to rapid changes in the business environment, quality as a strategic concern for business owners, and managerial ownership of quality. By analysing these challenges, six propositions for future research were proposed to reduce potential relevance gaps. Future research should focus on how to make QM a strategic concern for owners, and explore how it can contribute to organisational ambidexterity and adaptability. Research should also determine how context influences the way QM is applied, and investigate how it can improve organisational learning and innovation. Finally, research should indicate how top managers can adopt the responsibilities of quality managers, and explore the ways the principal values of QM can be better integrated into organisations.
\end{abstract}

Keywords: Quality management, Relevance gap, Delphi study, Organisational adaptability, Ambidexterity 


\section{Introduction}

With its emphasis on the practical application of statistical tools, quality management (QM) has long been a key issue in both the private and the public sectors (see Michaels, 1964; Morrison, 1957; Shewhart, 1931, 1939; Taguchi and Wu, 1979). QM is applied in an array of service settings (Nilsson-Witell and Fundin, 2005), including healthcare (Talib et al., 2011), digitally connected services (Chen, 2008), and schooling (Fernández Cruz et al., 2016). In addition to the industry domains where it has an impact, many academic fields have produced research on QM; these include operations management (Zeng et al., 2017; Sousa and Voss, 2002), applied statistics (Hoerl and Snee, 2010), and management science (Douglas, 2001). Recent research on QM in the International Journal of Production Economics has been connected to many other domains, such as impact on innovation (Zeng et al., 2015, 2017), company performance (O’Neill et al., 2016; Phan et al., 2011; Wu and Zhang, 2013), and corporate social responsibility (Parast and Adams, 2012). Other fields include environmental management (Jackson et al., 2016; Wiengarten and Pagell, 2012), supply chain management (El Ouardighi, 2014), and implementation approaches (McAdam et al., 2016; Haffar et al., 2016).

QM shows a spectrum of perspectives regarding its impact on efficiency, stability, and standardisation to its impact on effectiveness, development, and innovation (Backström et al., 2017). The ability to combine the two ends of this spectrum seems, however, difficult to implement in practice. This is, perhaps, surprising, given that quality improvement for practitioners' customers was the original purpose of QM (Fundin et al., 2017). While ISO 
9001 has been widely implemented globally (Guler et al., 2002), practitioners often stress that standardisation impedes innovation (Eriksson et al., 2016).

The challenge of combining quality and innovation is not new. Fundin et al. (2017) suggested that such a challenge can be called the quality dilemma, similar to the productivity dilemma proposed by Abernathy (1978). Benner and Tushman (2003, 2015), along with the productivity dilemma, also addressed the challenge of how to combine exploration and exploitation. QM research in small- and medium-sized enterprises shows, however, that it is easier to find collaborative ways of combining standardisation and innovation in cultures nurtured organically, rather than mechanistically (Harris et al., 2013; McAdam et al., 2014). McAdam et al. (2014) found that leadership, culture, product lifecycles, and propensity to innovate interact with knowledge acquisition and assimilation, total quality management (TQM), and external knowledge sharing to foster innovation capabilities. Pinho (2008) also showed that consumer orientation affects innovation. However, no statistical evidence confirms the impact of TQM on innovation.

Despite its popularity as an area of research, many have criticised QM scholars for lacking empirical rigour (Sousa and Voss, 2002). For example, Klefsjö et al. (2008) indicated that different researchers have used several definitions of QM, making it difficult to conclusively evaluate the concept and the results of related studies, while Giroux (2006) suggested that the ambiguity associated with QM is intentional, adding to its usefulness as a concept. Indeed, throughout QM research approaches based on grounded theory (Glaser and Strauss, 1967), theory and practice have long developed inductively. This line of thought contends that the ambiguity intrinsic to past research on QM can help develop the concept with positive 
connotations. Despite this potential benefit, such conceptual ambiguity also allows managers to retain plausible deniability if the expected business-related outcomes are not realised.

ISO-series standards are the most widely used QM-related systems, with more than 1.3 million adopters of ISO 9001 and 14001 (Heras-Saizarbitoria and Boiral, 2013). The ISO 9001 system is considered useful because of its capacity to stabilise organisations. That said, mass production is different from service production, and QM approaches useful for the former may be unsuitable for the latter, indicating a need for contingency studies in the QM domain (Dean and Bowen, 1994; Sitkin et al., 1994; Sousa and Voss, 2002).

Several researchers have discussed the relevance gap in management research related to practical needs and challenges (e.g. Carter, 2008; de-Margerie and Jiang, 2011; Hodgkinson and Rousseau, 2009; Huff, 2000a, 2000b; Starkey and Madan, 2001; Walsh et al., 2007); there is an urgent need to explore relevance gaps to guide academics in the development of QM. However, bridging relevance gaps once identified can be challenging. Kieser and Leiner (2009) argued that traditional methods for overcoming relevance gaps (e.g. action research) are insufficient and that 'researchers and practitioners cannot collaboratively produce research, they can only irritate each other' (p. 516). Hodgkinson and Rousseau (2009) disagreed, claiming that collaborative research approaches have proven not only empirically rigorous but useful as well.

In a study of 225 Hong Kong-based electronics companies, Yeung et al. (2004) showed how QM practices align to operational goals. Despite this positive finding, however, the authors also found significant misalignment between QM theory and practice, mainly owing to the dynamic, fast-changing operational environment. Given that the Yeung et al. (2004) study 
was (a) conducted more than a decade ago and (b) based on a single industry in a single geographic area, it would be valuable to revisit the question of whether QM research and practice are misaligned. As such, this study aims to identify the challenges experienced by QM practitioners to better understand how contemporary QM research addresses them. Further, we suggest approaches to bridge the potential relevance gaps between research and practice. Four research questions guide the research to achieve these interrelated goals:

- What challenges related to QM do practitioners experience (or anticipate)?

- Can these challenges be organised into overarching themes?

- How does QM research address the themes of the challenges?

- What type of QM research can respond to the identified challenges?

To answer these questions, we organise the remainder of the paper into a series of interrelated sections. Next, we discuss our methods, and review the literature on the Delphi technique. In section 3, we analyse the results of the Delphi study to identify the themes of the QM challenges, and present studies that have explored these challenges. We then offer some propositions for future QM research in section 4. We conclude the study in section 5.

\section{Methodology}

We conduct our investigation through a Delphi study (inductively) and subsequent literature review (deductively). Figure 1 provides a visual representation of our study. 


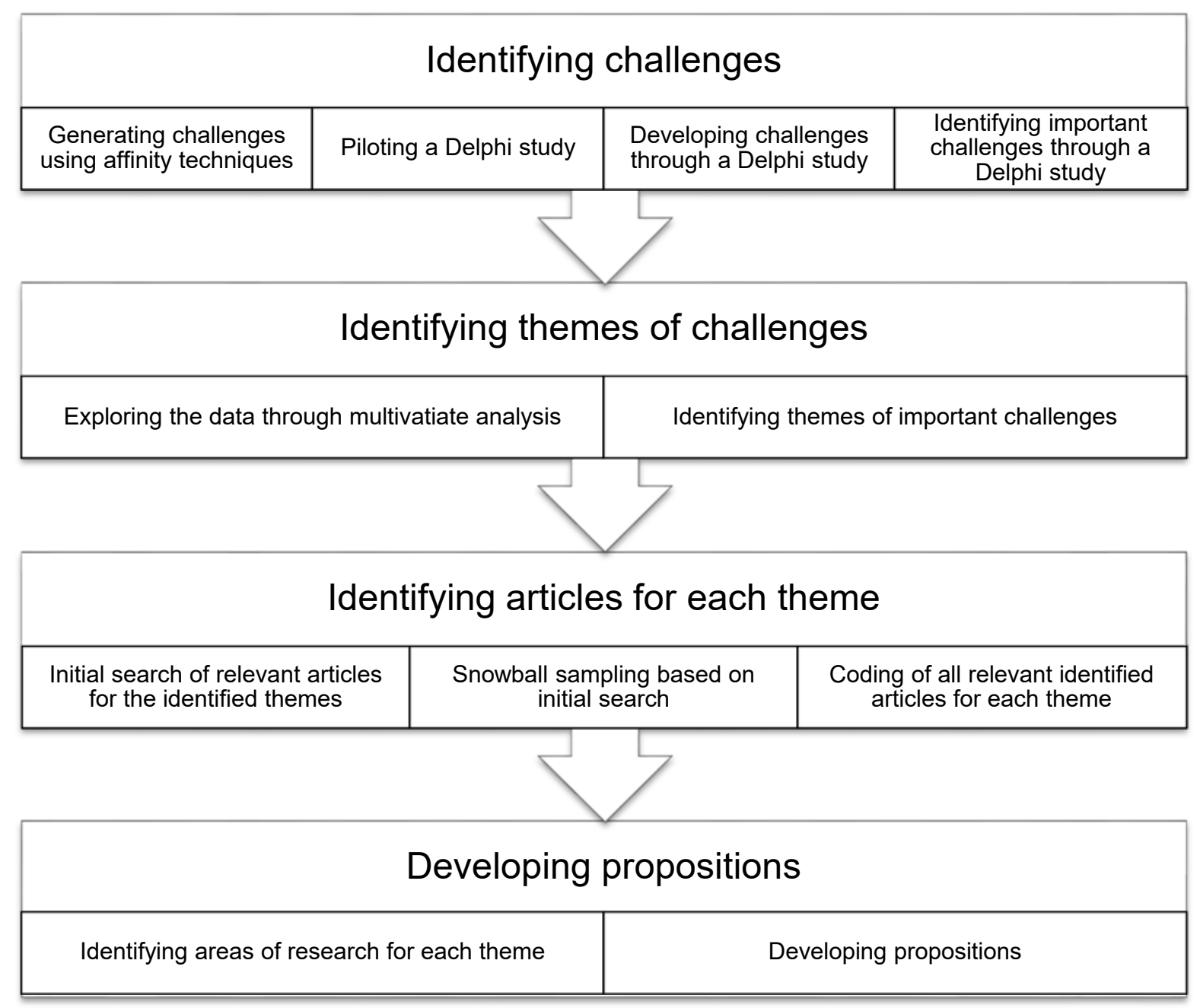

Figure 1. Four main phases of the study.

\subsection{Delphi study}

Our use of the Delphi study method is inspired by similar work by the American Society for Quality (ASQ, 2013). The Delphi method is an interactive approach that seeks to produce consensus among a group of experts (Rescher, 1998). Since we approached experts through e-mail and online web surveys, this study could be said to use an e-Delphi method (Keeney, 2010). 


\subsubsection{Generation of the initial challenges}

To initiate the study, we asked 12 colleagues (Swedish-based researchers with extensive experience active in the QM field) to participate in a workshop to generate a list of significant future QM challenges using affinity techniques. Each researcher described challenges on different Post-it ${ }^{\circledR}$ notes. Subsequently, the group clustered the notes according to affinity. The Post-it ${ }^{\circledR}$ notes were then reviewed and reformulated into standardised language and scope to avoid challenges with similar content. This stage produced 65 challenges.

\subsubsection{Pilot Delphi study}

We next performed a pilot Delphi study to test and improve the methodology, and develop the list of challenges. In this stage, 17 QM researchers participated in a pilot e-Delphi study, which involved three rounds. The researchers could rank the 10 most significant challenges, motivate the reasons for their choice, and provide new challenges for each round. In this way, we could add new challenges and withdraw challenges not believed to be important after each round. The researchers also provided feedback to clarify the methodology. At the end of the pilot study, 38 challenges remained after a final review that removed those with similar content.

\subsubsection{Delphi study}

An essential step in a Delphi study is the selection of experts. We identified 357 individuals on our and the QM researchers' networks. The individuals were selected based on their comprehensive experience of QM and ability to provide an overview of their business 
branches. Respondents had different positions, including quality managers, development managers, general managers, CEOs, product development managers, unit managers, consultants, IT specialists, and researchers. To maximise engagement, we sent the questionnaire to all 357 respondents in all rounds. This approach provided a more nuanced and comprehensive collection of challenges instead of excluding respondents and challenges. Respondents were asked: 'Based on your collective experience with organisations in Sweden, select 10 challenges from the list you think will be most important over a 10-year period and justify your selection'. A total of 188 respondents, from both the private sector $(n=111)$ and the public sector $(\mathrm{n}=77)$, participated. Of the 111 respondents from the private sector, 53 worked in companies that manufactured goods and 58 worked for companies that provided services. Altogether, 59 respondents worked for companies with domestic operations and 52 worked for companies with international operations.

In the first $(n=142)$ and second steps $(n=122)$ of the Delphi process, respondents could suggest additional challenges to be added to the initial list. The suggested challenges (173 challenges were proposed after the first step and 140 after the second step) were analysed, grouped, reformulated, and added to the next step if three, or more respondents provided similar content and existing challenges did not cover the content. Nine challenges were added to the second step and two to the third. Challenges not identified as being among the 10 most important were removed. In the third step, respondents were also asked to rank the 10 most important challenges for the next 10 years based on the list and motives. In this last stage $(n=126), 49$ challenges were ranked by at least one of the respondents. 


\subsection{Statistical analysis}

Although the Delphi study revealed several interesting challenges as perceived by respondents, underlying similarities among participants' perceptions remained. Given this, we considered exploratory factor analysis (EFA) to be an appropriate first step in the analysis, as an EFA could address the research question related to the themes of the challenges. Given that participants may have (a) had problems interpreting some of the presented challenges or (b) considered some of the presented challenges to be similar, the data were suitable for a reduction of dimensionality through the extraction of underlying factors. As such, we used SPSS (v. 24) to perform the EFA with principal component extraction and Varimax rotation (Institute for Digital Research and Education, 2016). This method maintained the orthogonality of the rotated components (Johnson and Wichern, 1992). The EFA was based on the unscaled covariance matrix, rather than the correlation matrix, since we wanted to let challenges ranked as important by respondents influence the model more than those ranked as less important.

However, social sciences data are often non-normal, and violations of the normality assumption can affect how a factor analysis is performed and interpreted (e.g. determining how many factors to retain). Decisions about when it is best to reduce data further (i.e. after extraction or rotation) can also affect the results of an EFA (Comrey, 1978). One common method is retaining those extracted principal components with eigenvalues greater than 1 , which contain more information than a single variable (Guttman, 1954). Mote (1970) demonstrated that retaining a large number of components before rotation can generate a 
more meaningful interpretation of the rotated solution, implying that the 'eigenvalue $>1$ rule' produces too few components. Others have found this rule to overestimate the number of components to be retained (e.g. Browne, 1968).

Another method of selecting the number of components to retain is Cattell's (1966) Scree method. The Scree method involves plotting components' eigenvalues and identifying those components that deviate from the smallest ones (as identified by a visual determination). Moreover, the analysis of a Scree plot involves identifying a visible 'knee', whereby eigenvalues that form a straight line drawn through the smaller eigenvalues are retained. If the observations are normally distributed, the eigenvalues produced from the covariance matrix tend to follow a Wishart distribution (Wachter, 1976). We adapted the Scree plot to acknowledge this by using Wachter's modification (Wachter, 1976), which accounts for errors due to non-normally distributed observations. With or without the Wachter modification, the Scree plot becomes troublesome if it does not provide a clear indication of how many factors to retain, as evidenced by the aforementioned 'knee' that distinguishes eigenvalues likely to contain noise. Concerning sample size, some researchers have argued that a factor analysis should be performed with a sample of no less than 200 and that a sample size of 100 is too low. At the least, the sample should be sufficient to produce 10 observations per variable (Comrey and Lee, 1992). Using Comrey and Lee’s (1992) guideline, our sample of 188 respondents is sufficient to perform a factor analysis that includes 10 variables.

After extracting the components, Bartlett's test of sphericity and the Kaiser-Meyer-Olkin measure of sampling adequacy (KMO) were used to evaluate if the models are useful (see Table A1). As general rules, useful models have significant Bartlett's tests and KMO 
statistics greater than 0.6 (although values greater than 0.8 are considered to be good, see Kaiser, 1974). Bartlett's test has been shown to successfully identify even small differences between eigenvalues when sample are large (Gorsuch, 1973, 1974).

\subsection{Literature review}

To perform the literature review, we used the Web of Science (WoS) database because of its extensive collection spanning disciplines including QM. WoS contains articles from about 12,700 international and regional journals from the Science Citation Index Expanded index, Social Sciences Citation Index, and Arts \& Humanities Citation Index. Our sample consists of articles published between 2006 and 2017, and is limited to journal articles in English. We conducted our search based on the three most important themes that resulted from our analysis of the Delphi study. Table 1 summarises the search strategies for each article.

Table 1. Literature search strategies.

\begin{tabular}{llll}
\hline Theme & Keywords and & WoS refinement by research & Journals with 2+ articles \\
& truncations & field & \\
& & \\
\hline
\end{tabular}




\begin{tabular}{|c|c|c|c|}
\hline \multirow[b]{4}{*}{ Making an } & & Management, Business, & Total Quality Management \\
\hline & & Operations research management & \& Business Excellence, \\
\hline & & science, Psychology applied, & Organization Studies, \\
\hline & 'quality & Engineering industrial, Healthcare & Journal of Operations \\
\hline organisation agile and & management' & sciences services, Health policy & Management, International \\
\hline adaptable to rapid & AND adapt* & services, Social sciences & Journal of Production \\
\hline \multirow[t]{5}{*}{ changes in the business } & AND & interdisciplinary, Engineering & Economics, International \\
\hline & organisation* & manufacturing, Planning & Journal for Quality in \\
\hline & & development, Economics, & Health Care, Journal of \\
\hline & & Engineering multidisciplinary or & Health Organization and \\
\hline & & Engineering mechanical & Management \\
\hline \multirow{10}{*}{ Making quality a } & & Management, Healthcare sciences & \\
\hline & & services, Engineering civil, & \\
\hline & & Engineering manufacturing, & \\
\hline & & Operations research management & \\
\hline & & science, Planning development, & Total Quality Management \\
\hline & & Engineering mechanical, & \& Business Excellence \\
\hline & & Construction building technology, & \\
\hline & & Multidisciplinary sciences, & \\
\hline & & Business or Health policy & \\
\hline & & services & \\
\hline
\end{tabular}




\begin{tabular}{llll}
\hline & & & Total Quality Management \\
& & Sociology, Management, & and Business Excellence, \\
& & Engineering industrial, & International Journal of \\
Transferring the & Engineering civil, Engineering & Operations and Production \\
'quality & management' & multidisciplinary, Operations & Management, Quality \\
from quality & research management science, & Engineering, Journal of \\
professionals to & AND & Engineering manufacturing, & Professional Issues in \\
management & Business, Behavioural sciences, & Engineering Education and \\
& Business economics, Engineering, & Practice, Journal of \\
& and Psychology & & Construction Engineering
\end{tabular}

Literature reviews are often categorised as narrative reviews, systematic reviews, and metaanalyses (Rhoades, 2011). The first type focusses on summarising the literature on a certain topic without systematic selection, coding, or criteria (Rhoades, 2011, Grosse et al., 2015). The second type is based on the systematic application of rigorous criteria for selection and analysis, and the third type focusses on an aggregate review of the results of studies of a certain topic (Rhoades, 2011, Grosse et al., 2015).

This study employs a three-step systematic review method: review abstracts, full paper review, and coding. Systematic reviews are suitable as they increase methodological rigour for academics, while helping practitioners' base knowledge on the accumulated findings from many studies (Tranfield et al., 2003). Hence, a systematic review can be argued to be 'at the heart of a "pragmatic" management research, which aims to serve both academic and practitioner communities' (Tranfield et al., 2003, p. 220). 
However, before performing the review based on the search string, we chose to limit the searched journals to those we felt contributed to the QM discourse. This selection has some traits of a narrative review, as these 'draw together major arguments in a field of discourse' (Rhoades, 2011, p. 62). To guarantee that the particular challenge was addressed from a QM perspective, articles selected had to be published in a journal judged to be a part of the QM discourse. In practice, this meant that we retained articles from journals in which we found at least two articles related to one of the identified challenges. Hence, the review can be classified as having a coverage that aimed to be exhaustive with a selective citation and subsequently based on an analysis of a selected sample of works (Hochrein and Glock, 2012; Hochrein et al., 2015), as shown in Table 2.

Table 2. Overview of the literature review: Classification criteria proposed by Hochrein and Glock (2012) and Hochrein et al. (2015).

\begin{tabular}{ll}
\hline Criteria & Description \\
\hline Focus & The focus of the review is on the research findings. \\
\hline Goal & The goal of the literature review is to analyse how \\
& QM research addresses the challenges related to QM \\
& that practitioners reported on in the Delphi study; in \\
& other words, the goal was identifying central themes \\
\hline in the research on each challenge.
\end{tabular}


The process by which articles were identified and evaluated comprised three main steps. First, we reviewed articles based on their associated abstracts. Second, if an article's abstract appeared to be relevant, we reviewed the full article. Third, the full article was coded into one of three categories, and its purpose, method, contributions, and suggested future research directions were summarised. We also used a snowball sampling method to find other relevant articles through the references of the coded articles. In total, 44 articles were found based on their abstracts, of which only 12 were coded as relevant to the challenges derived from the Delphi study. The snowball sampling method thus produced an additional 59 references, 26 of which were relevant. The final sample thus consisted of 38 articles.

All the authors read and coded the articles in up to three rounds to ensure their relevance and obtain a second and third opinion on them if necessary. The first round included all 38 articles that were randomly distributed among those that had not made the original review and classification. Articles could be coded as (1) not relevant, (2) relevant to the identified challenges, or (3) relevance needs to be discussed. In the second round, 16 of the 38 articles were not coded consistently across the two coders. When coders disagreed on an article's classification, a third reader coded the article to break the tie. This method produced a final list of 29 relevant articles.

\section{Results}

\subsection{Development of the main themes of the challenges}

The Delphi study identified 49 challenges, which the EFA reduced to three main themes. When all 49 challenges are included in the model, Bartlett's test is significant, but the KMO 
test produced a measure well below the accepted standard $(\mathrm{KMO}=0.164)$. This low KMO value indicates that a factor analysis would not sufficiently describe the variation in the data. This may be the result of the sampling method, whereby respondents were only permitted to rate 10 of the 49 challenges as important. Due to this restriction, the observation matrix contains a substantial number of zero entries. Hence, the ranking system may have caused the data to be skewed. We weighted participants' rankings such that their highest-ranked challenge received a score of 1 , their second-highest ranking received a score of $1 / 2$, and their third-highest ranking received a score of $1 / 3$, and so on. By using this approach, we weighted the rankings such that the highest-ranked challenge would stand out, and the $9^{\text {th }}$ challenge would not be perceived as twice as important as the $10^{\text {th }}$. The resulting data are not normally distributed because of our approach.

Extracting components from data for which most matrix elements are zero generates poorfitting models. If, however, only the 10 highest-ranked challenges are selected as a subsample, the matrix will contain larger proportions of rated to unrated challenges for each respondent. Therefore, the component extraction is less encumbered by the zeroes filling the matrix. Indeed, this approach increased the KMO statistic to 0.486. Although this is still quite low, it is a marked increase from the KMO statistic resulting from the model that included all 49 challenges. However, using only the top 10-ranked variables rendered Bartlett's test nonsignificant, suggesting that these are only weakly correlated.

By iteratively removing non-significant variables, the KMO improved to 0.52 and Bartlett's test became significant. Based on the Scree plot (see Figure A1), we selected three components that collectively explained $75 \%$ of the remaining variation (see Table A2). Table 
3 shows the results of the Varimax-rotated components (see also Tables A2-A4). Rescaled factor component loadings less than 0.1 have been suppressed.

Table 3. Rotated Component Matrix ${ }^{\mathrm{a}}$.

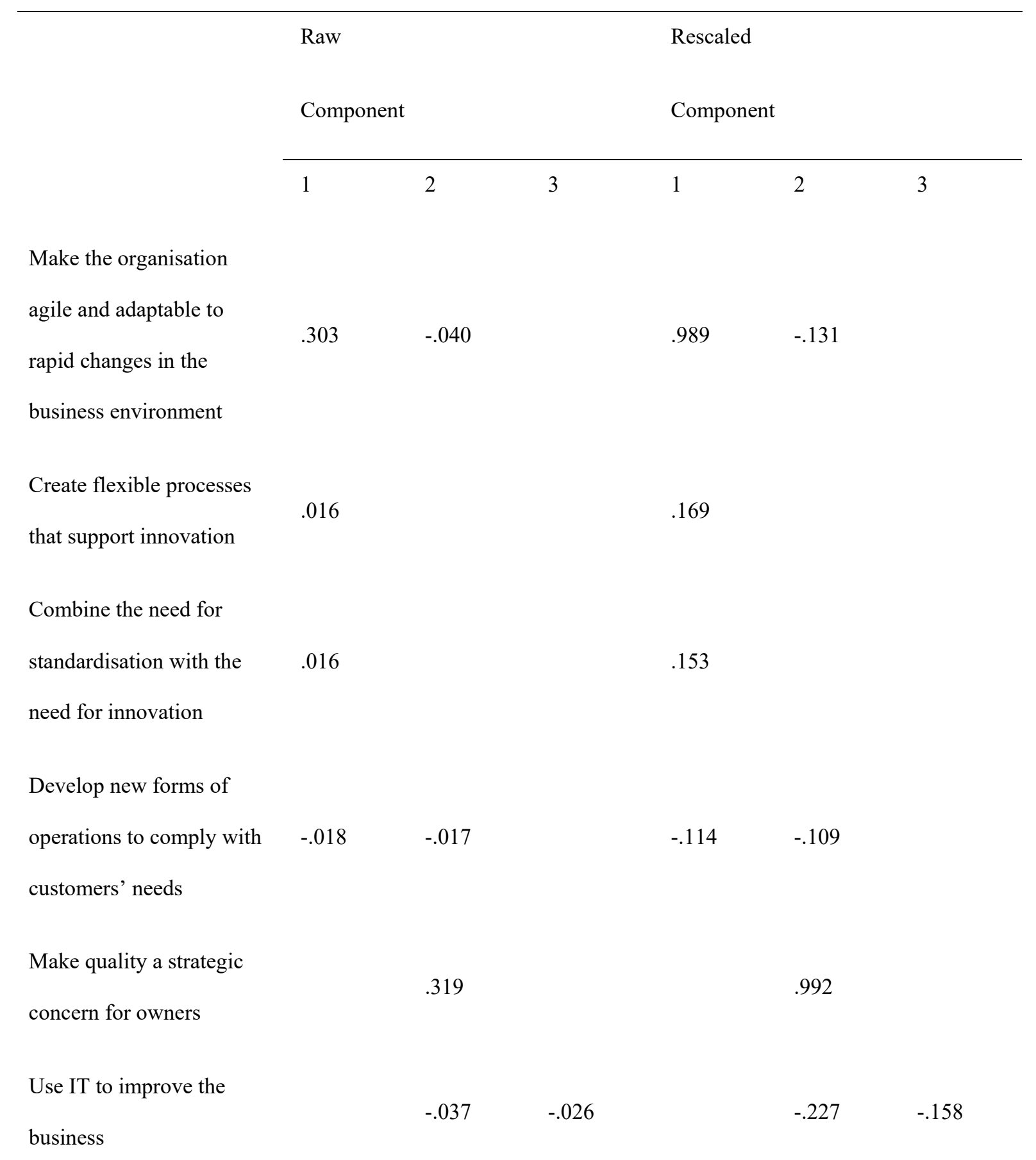




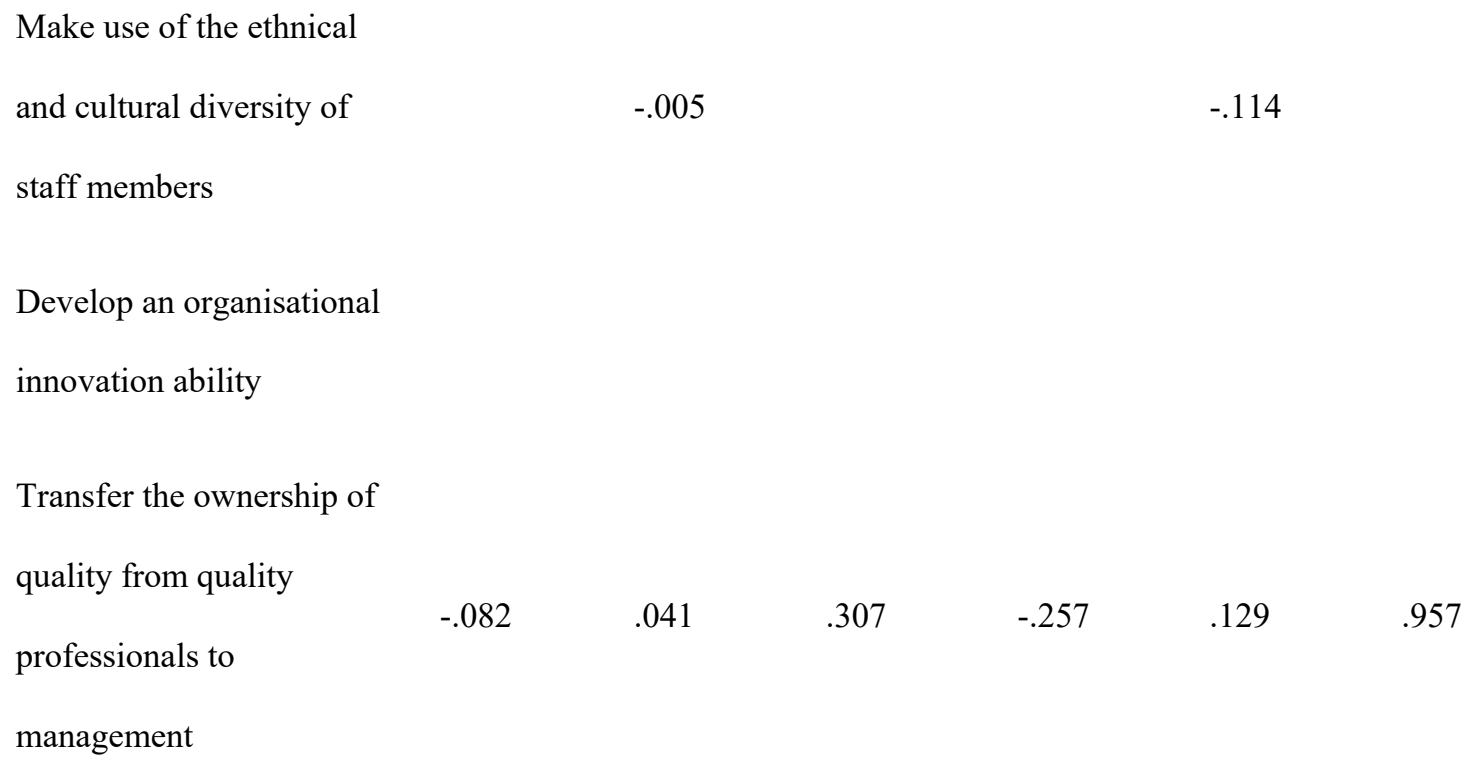

Looking at the extracted components, the first rotated factor relates to the exploratory measurement of innovation (although still with an internal process perspective). The dominant theme of the first factor is making an organisation agile and adaptable to rapid changes in the business environment. The factor also contains items related to the urge to create flexible processes and the combination of needs for standardisation and innovation (although these loadings are relatively weak). One challenge - the need to develop new forms of operations to address customer needs-loaded negatively onto this first factor.

The second factor relates closely to board outreach, and addresses a fundamental question: how do we involve owners in processes related to quality? For this second factor, the dominant theme relates to making quality a strategic concern for owners. Respondents that seek the involvement of owners tend to ask for more involvement from top managers as well. Some challenges loaded negatively onto the factor, including the internal focus of 
adaptability and use of IT and diversity of the workforce. These issues are often prioritised by those that seek greater support from owners on efforts related to QM.

The third component measures the difficulty some respondents perceive in getting managers to adopt responsibility for quality. The main theme of the challenges that comprise this factor is transferring the ownership of quality from quality professionals to management. By using these three themes as a guide, we conducted a literature review to determine the degree to which the literature addresses them.

\subsection{Literature review results}

The literature review resulted in $29 \mathrm{WoS}$-indexed articles clustered into five research areas. Nineteen articles clustered into the organisational agility and adaptability factor (Factor 1), and were further classified into three subcategories: Ambidexterity, Contextualisation, and Learning and Innovation. Ten articles clustered into the factor concerning transferring quality ownership to managers (Factor 2), and were further classified into two subcategories: Responsibility and Drivers. We did not identify any articles concerning the factor related to making quality a strategic concern for owners (Factor 3).

\subsubsection{Making organisations agile and adaptable to rapid environmental changes}

Extant research related to Factor 1 has been performed in the fields of organisation theory, innovation management, and operations management. Table 4 summarises this research. 

Table 4. Literature addressing organisational agility and adaptability to rapid environmental changes.

\begin{tabular}{|c|c|c|c|c|c|c|c|}
\hline \multirow{2}{*}{ Research area } & \multirow{2}{*}{ Study } & \multirow{2}{*}{ Journal } & \multirow{2}{*}{ Purpose } & \multirow{2}{*}{ Method } & \multicolumn{2}{|c|}{ Contributions and implications } & \multirow{2}{*}{ Future research } \\
\hline & & & & & Theoretical & Managerial & \\
\hline Ambidexterity & $\begin{array}{l}\text { Asif and de } \\
\text { Vries } \\
\text { (2015) }\end{array}$ & $\begin{array}{l}\text { Total Quality } \\
\text { Management \& } \\
\text { Business Excellence }\end{array}$ & $\begin{array}{l}\text { Exemplify ambidextrous } \\
\text { QM }\end{array}$ & $\begin{array}{l}\text { Literature } \\
\text { review }\end{array}$ & $\begin{array}{l}\text { Exploration of perspectives } \\
\text { on QM practices }\end{array}$ & $\begin{array}{l}\text { Ambidextrous QM can be } \\
\text { managed strategically }\end{array}$ & $\begin{array}{l}\text { Critical processes to } \\
\text { achieve ambidextrous } \\
\text { QM }\end{array}$ \\
\hline Ambidexterity & $\begin{array}{l}\text { Asif et al. } \\
\text { (2013) }\end{array}$ & $\begin{array}{l}\text { Total } \\
\text { Quality Management } \\
\text { \& Business } \\
\text { Excellence }\end{array}$ & $\begin{array}{l}\text { Investigate how QM } \\
\text { correlates with } \\
\text { knowledge creation and } \\
\text { innovation }\end{array}$ & $\begin{array}{l}\text { Literature } \\
\text { review }\end{array}$ & $\begin{array}{l}\text { Identification of six QM } \\
\text { practices that contribute to } \\
\text { innovation }\end{array}$ & $\begin{array}{l}\text { QM has elements of } \\
\text { innovation from a knowledge } \\
\text { perspective }\end{array}$ & $\begin{array}{l}\text { Validate results with case } \\
\text { studies }\end{array}$ \\
\hline Ambidexterity & $\begin{array}{l}\text { Behmer et } \\
\text { al. (2016) }\end{array}$ & $\begin{array}{l}\text { Total } \\
\text { Quality Management } \\
\text { \& Business } \\
\text { Excellence }\end{array}$ & $\begin{array}{l}\text { Present challenges, } \\
\text { motives, and success } \\
\text { factors of planning } \\
\text { and reorganising QM } \\
\text { organisations }\end{array}$ & Survey & $\begin{array}{l}\text { Outdated QM organisations } \\
\text { are unable to adapt to a } \\
\text { dynamic environment }\end{array}$ & $\begin{array}{l}\text { Ideas for new proactive, } \\
\text { comprehensive, and long- } \\
\text { term-oriented concepts to } \\
\text { improve the flexibility and } \\
\text { effectiveness of QM in } \\
\text { manufacturing }\end{array}$ & $\begin{array}{l}\text { The role of QM for } \\
\text { entrepreneurial success } \\
\text { in reorganisations based } \\
\text { on digitalisation in } \\
\text { manufacturing }\end{array}$ \\
\hline Ambidexterity & $\begin{array}{l}\text { Benner and } \\
\text { Tushman } \\
\text { (2003) }\end{array}$ & $\begin{array}{l}\text { Academy of } \\
\text { Management Review }\end{array}$ & $\begin{array}{l}\text { Review the productivity } \\
\text { dilemma of exploitation } \\
\text { and exploration in }\end{array}$ & $\begin{array}{l}\text { Literature } \\
\text { review }\end{array}$ & $\begin{array}{l}\text { Exploratory activities must } \\
\text { strengthen process } \\
\text { management; ambidextrous }\end{array}$ & $\begin{array}{l}\text { Process management is } \\
\text { beneficial for organisations in } \\
\text { stable contexts. Dynamic }\end{array}$ & $\begin{array}{l}\text { Empirical tests of the } \\
\text { propositions }\end{array}$ \\
\hline
\end{tabular}


process management

\begin{tabular}{|c|c|c|c|c|}
\hline \multirow{3}{*}{ Ambidexterity } & \multirow{2}{*}{$\begin{array}{l}\text { Gupta et al. } \\
\text { (2006) }\end{array}$} & & & \multirow{3}{*}{$\begin{array}{l}\text { Literature } \\
\text { review }\end{array}$} \\
\hline & & Management & between exploration and & \\
\hline & & Journal & exploitation & \\
\hline
\end{tabular}

Ambidexterity

Hsu et al.

Total Quality

(2007)

Management \&

Business Excellence

Show the difference

between exploitation and Literature

exploration in the

review

practice of TQM organisations provide the

capabilities are rooted in both

complex contexts needed

exploitative and exploratory

for the coexistence of these

activities

Depending on the context,

either ambidexterity or

Both exploration and

exploitation involve

different degrees of

learning. Exploration and

exploitation can be treated

as two ends of a continuum

or orthogonal depending on

single or multiple domains

punctuated equilibrium may

Studies that examine

serve as a more appropriate

exploration and

balancing mechanism

exploitation at a micro

between exploration and

level, studies spanning

exploitation. Balancing

multiple levels of

analysis, and studies that

examine the challenges

associated with

level systems, and each

achieving a balance

subsystem can focus on just

between exploration and

exploration or just

exploitation

exploitation without any

major threats to long-run

performance

Exploration is associated with

weak-tie partners, organic

structures, chaotic culture, 
is associated with

mechanistic structures, tightly

controlled systems,

organisational memory

bureaucracy, and stable

markets

Process management may be

what helps lead TQM to

Case studies for better

Explain how cultural

Moreno- Total Quality divergence driven by

process management can

Survey

Ambidexterity

\section{Luzon et al. Management \&}

affect organisational

ambidexterity

Defined relationships

exploration, but process

understanding cultura

between values used to

management still leads more

constitute exploitation and

to exploitation. This implies

that there is an imbalance

towards exploitation within

TQM

change during the first

stages of the introduction

of process management,

as well as during the

consolidation stage, and

full maturity

QM practitioners have

\section{Moreno-}

Luzon and Management

Valls Pasola Decision

\section{Explore how QM could}

contribute to

ambidexterity

Literature

review

\section{QM has elements of}

innovation and abilities for

change based on QM

principles and practices

Discuss and problematise Literature

how organisations can review different focusses: either

exploration through

innovation and high speed of

QM and ambidexterity change based on customer

needs or exploitation only

Strategies for managing

ambidextrous organisations 
O'Reilly

(1996)

simultaneously evaluate

several products to

respond to customer

needs

Propose centrifugal and

centripetal forces as

metaphors to

Sheremata Academy of

(2000)

Management Review

successfully manage

radical, innovative

product development

projects

International Describe the Scalable

Temponi Journal of

(2006)

Production

Economics

to facilitate flexibility

and adaptability

Investigate how

contextual factors

Journal of

Contextualisation

Zhang et al.

(2012) influence the relationship

between QM practices

and manufacturing

performance ambidexterity to facilitate

the management of

changing customer needs

Problematising difficulties

A model that guides how

Propositions on how

associated with balancing

efficiency and effectiveness

centrifugal and

centrifugal and centripetal

could be balanced based on

centripetal forces affect

forces and how it affects

product quality and quality in

radical new produc

product quality

decisions

development

The SES may be useful for

simultaneously managing

exploration and

exploitation

Combining QM and business

Many different SESs to

process reengineering (BPR)

be defined depending on

is profitable

the business

Depending on environmental

Contributes to the

discussion on the universal

versus context-dependent

approach to QM

variable

effects of quality exploitation

and quality exploration on

manufacturing performance
Identifying more key

contingency variables in

the operations

management discipline 
Culture-building through

autocratic, organic,

enabling bureaucracy o

Strategies for organisational

coercive bureaucracy gives designs to enable employee

different prerequisites on

involvement

organisational readiness for

change
Investigate method-

driven and psychology-

driven mechanisms of

knowledge creation

Questionnaire

innovation

Science

\section{Explore the relationship}

between BPR, TQM, and

organisational learning

Literature

review
Learning behaviours affect

performance directly and

indirectly through

knowledge created

\section{Relative importance of} method and psychological mechanisms on learning behaviours and knowledge creation in quality projects

\section{BPR, TQM, and}

organisational learning have

Analysis of the correlation similar targets and common between TQM and

organisational learning

visions, but from

sustainability perspective,

based on system archetypes TQM is a profitable long-

term alternative because of

the system approach

Structural equation model Use of TQM principles has

direct or indirect connection

\section{Learning and}

innovation
(2003)

\section{Propose a structural}

equation model that 
shows the correlations

between TQM and

profitability

Explore the relationships

among QM practices and

Learning and

innovation

Kim et al.

Journal of

Operations

Management

practices are directly or

indirectly related to

innovation

\section{Compare organisational}

Steiber and Total Quality

Alänge

Management \&

innovation characteristics for

continuous innovation in Interviews

rapidly changing

industries with key TQM relationships between

TQM principles and firm

performance

Survey

QM practices are directly

and indirectly associated,

and the importance of

individual QM practices is

tied to other practices

and positively relates to all

Model of total and indirect

Control and chaos should $\quad$ Further trust in employees as

be balanced in a partly self- not only problem-solvers but

organised and semi-

structured organisation in knowledgeable decision-

which only a few processes makers with profitability

types of innovation

effects of QM practices on

innovations of various kinds.

Process management directly

and why QM practices

lead to innovation

also as innovators and

N/A

effectiveness

implementing TQM,

using criteria such as

organisational learning,

employee satisfaction,

decentralised structure,

and resource acquisition,

and degree of integration

with supplier bases

Further investigation of

firms with less-

developed quality

programmes, as well as

those not certified.

Investigations of how 
principles

Identify factors that

Learning and

innovation

$\begin{array}{ll}\text { Van } & \text { Journal of Health } \\ \text { Rossum et } & \text { Organization and } \\ \text { al. (2016) } & \text { Management }\end{array}$

enable lean

transformation in

healthcare are formalised, but

heuristic rules and probe-

and-learn processes are

common

Positive correlations

between transformational

leadership and team

leadership styles and lean

healthcare implementation.

The results also find

correlations between

workforce flexibility and

lean healthcare

Leadership and workforce

flexibility enhance an

organisation's

change capacity and

achieving sustainable

transformation

implementation 
First, the work by Levinthal and March (1993) on organisational ambidexterity has strongly influenced discussions on QM, particularly concerning the exploration/exploitation dilemma (Benner and Tushman, 2003, 2015). Hsu et al. (2007) stressed the importance of explaining the differences between exploration and exploitation in QM practices. Specifically, exploration is associated with weak-tie partners and autonomy, whereas exploitation is associated with tightly controlled systems and stable markets. Although firms tend to focus more heavily on exploitation as a means to reduce risk and variation in operational processes, QM practices include elements of both exploitation and exploration (Asif and de Vries, 2015). However, QM must be revised to enhance flexibility and adaptability (Behmer et al., 2016). The exploitation/exploration dichotomy has strategic implications for ambidextrous organisations in which exploratory activities support process management (Benner and Tushman, 2003). Moreno-Luzon et al. (2014) concluded that process management drives cultural divergence, which affects organisational ambidexterity, and leads to further exploitation. In other words, QM leans towards exploitation, provided that exploration is not a focal point of the specific organisational design.

Second, a substantial amount of research promotes contextualisation as a necessary process for promoting organisational agility and adaptability. Zhang et al. (2012) described how QM practices are context-dependent, with specific QM approaches being contingent on their business environment. They further suggested a contingency approach for adapting QM to specific environmental contexts. As an example, Sheremata (2000) proposed a model that focusses on organisational agility specifically for radical product development with limited time. Moreover, Temponi (2006) described scalable enterprise systems that combine QM with BPR. Future research should thus examine different types of scalable enterprise systems for aiding QM (e.g. to promote management commitment to QM), depending on the 
businesses in which they are used (Temponi, 2006). Temponi's (2006) assertion stresses that contextual factors play a critical role in adapting QM.

Third, Kaynak (2003) demonstrated that TQM principles, directly and indirectly, affect profitability. This effect can be attributed to learning and innovation. Choo et al. (2007) similarly argued that organisational learning affects performance through the knowledge it creates. In a similar vein (although from a practical perspective), Asif et al. (2013) identified six QM practices that contribute to new knowledge and innovations. Organisational design factors also influence these QM practices (Steiber and Alänge, 2013). Steiber and Alänge (2013) suggested that control and chaos should be balanced in partly self-organised and semistructured organisations to foster continuous innovation. Only a few processes should be institutionalised in these organisations. Instead, heuristic rules and probe-and-learn processes should sometimes be allowed to guide innovation. Adler (1999) also proposed varying degrees of formalisation in organisational design to involve employees in innovative processes. In line with these ideas, Van Rossum et al. (2016) described how leadership and workforce flexibility can enhance an organisation's change capacity to achieve sustainable transformation. Finally, Dervitsiotis (1998) found that BPR, TQM, and organisational learning tend to have similar target outcomes and common visions.

\subsubsection{Transferring the ownership of quality from quality professionals to managers}

Researchers who have explored transferring quality ownership from quality professionals to management have primarily come from the fields of organisation theory and operations management. Table 5 provides an overview. 
Table 5. Literature related to transferring quality ownership from quality professionals to managers.

\begin{tabular}{|c|c|c|c|c|c|c|c|}
\hline \multirow[t]{2}{*}{ Research area } & \multirow[t]{2}{*}{ Study } & \multirow[t]{2}{*}{ Journal } & \multirow[t]{2}{*}{ Purpose } & \multirow[t]{2}{*}{ Method } & \multicolumn{2}{|l|}{ Contributions and implications } & \multirow[t]{2}{*}{ Future research } \\
\hline & & & & & Theoretical & Managerial & \\
\hline Responsibility & $\begin{array}{l}\text { Bayo- } \\
\text { Moriones and } \\
\text { Merino-Diaz } \\
\text { de Cerio } \\
(2003)\end{array}$ & $\begin{array}{l}\text { International } \\
\text { Journal of } \\
\text { Quality \& } \\
\text { Reliability } \\
\text { Management }\end{array}$ & $\begin{array}{l}\text { Determine the role of } \\
\text { the quality department } \\
\text { in Spanish industrial } \\
\text { firms }\end{array}$ & Survey & $\begin{array}{l}\text { Quality departments are often } \\
\text { placed high up in the } \\
\text { organisational hierarchy in } \\
\text { medium-sized or } \\
\text { multinational companies. } \\
\text { Smaller companies do not } \\
\text { afford as much influence to } \\
\text { the quality department }\end{array}$ & N/A & $\begin{array}{l}\text { The impact of the } \\
\text { quality department at } \\
\text { various levels of QM } \\
\text { implementation and its } \\
\text { status }\end{array}$ \\
\hline Responsibility & $\begin{array}{l}\text { Burcher et al. } \\
(2008)\end{array}$ & $\begin{array}{l}\text { The TQM } \\
\text { Journal }\end{array}$ & $\begin{array}{l}\text { Compare and contrast } \\
\text { the career experiences } \\
\text { and development needs } \\
\text { of British and } \\
\text { Australian quality } \\
\text { managers }\end{array}$ & Survey & $\begin{array}{l}\text { Lack of innovatory zeal } \\
\text { among quality managers who } \\
\text { appear to be more concerned } \\
\text { with the maintenance of } \\
\text { standards than taking a more } \\
\text { dynamic approach }\end{array}$ & $\begin{array}{l}\text { While quality } \\
\text { managers bring wide } \\
\text { functional experience } \\
\text { to their current roles, } \\
\text { many do not possess } \\
\text { cutting-edge } \\
\text { knowledge in their } \\
\text { field. }\end{array}$ & $\mathrm{N} / \mathrm{A}$ \\
\hline Responsibility & $\begin{array}{l}\text { Camison and } \\
\text { de las Peñas }\end{array}$ & $\begin{array}{l}\text { Total Quality } \\
\text { Management }\end{array}$ & $\begin{array}{l}\text { Review the views of } \\
\text { CEOs and quality }\end{array}$ & $\begin{array}{l}\text { Delphi } \\
\text { survey and }\end{array}$ & $\begin{array}{l}\text { CEOs and quality managers } \\
\text { have different views }\end{array}$ & $\begin{array}{l}\text { Quality managers must } \\
\text { be adaptable to new }\end{array}$ & N/A \\
\hline
\end{tabular}


interviews

roles

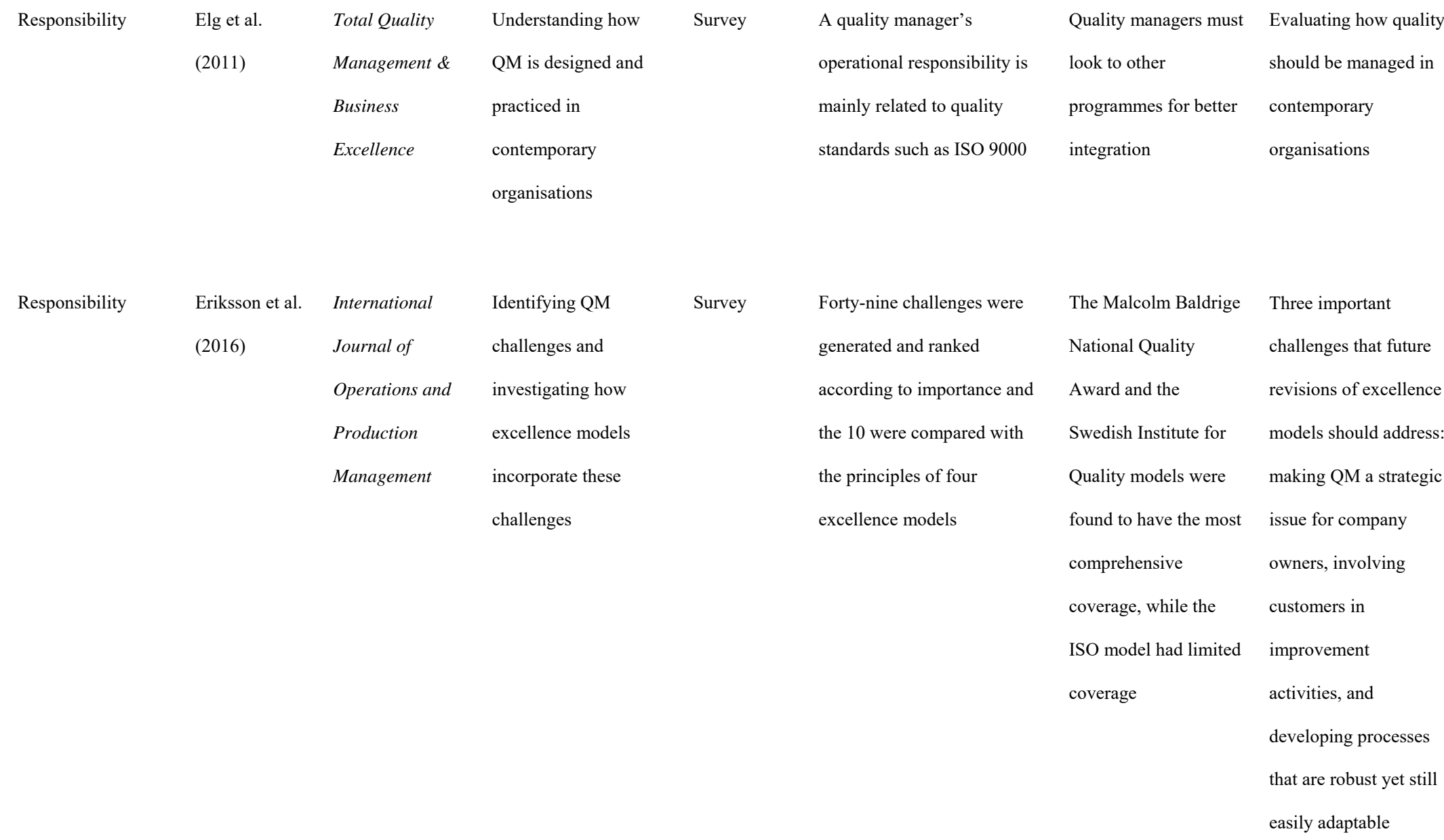




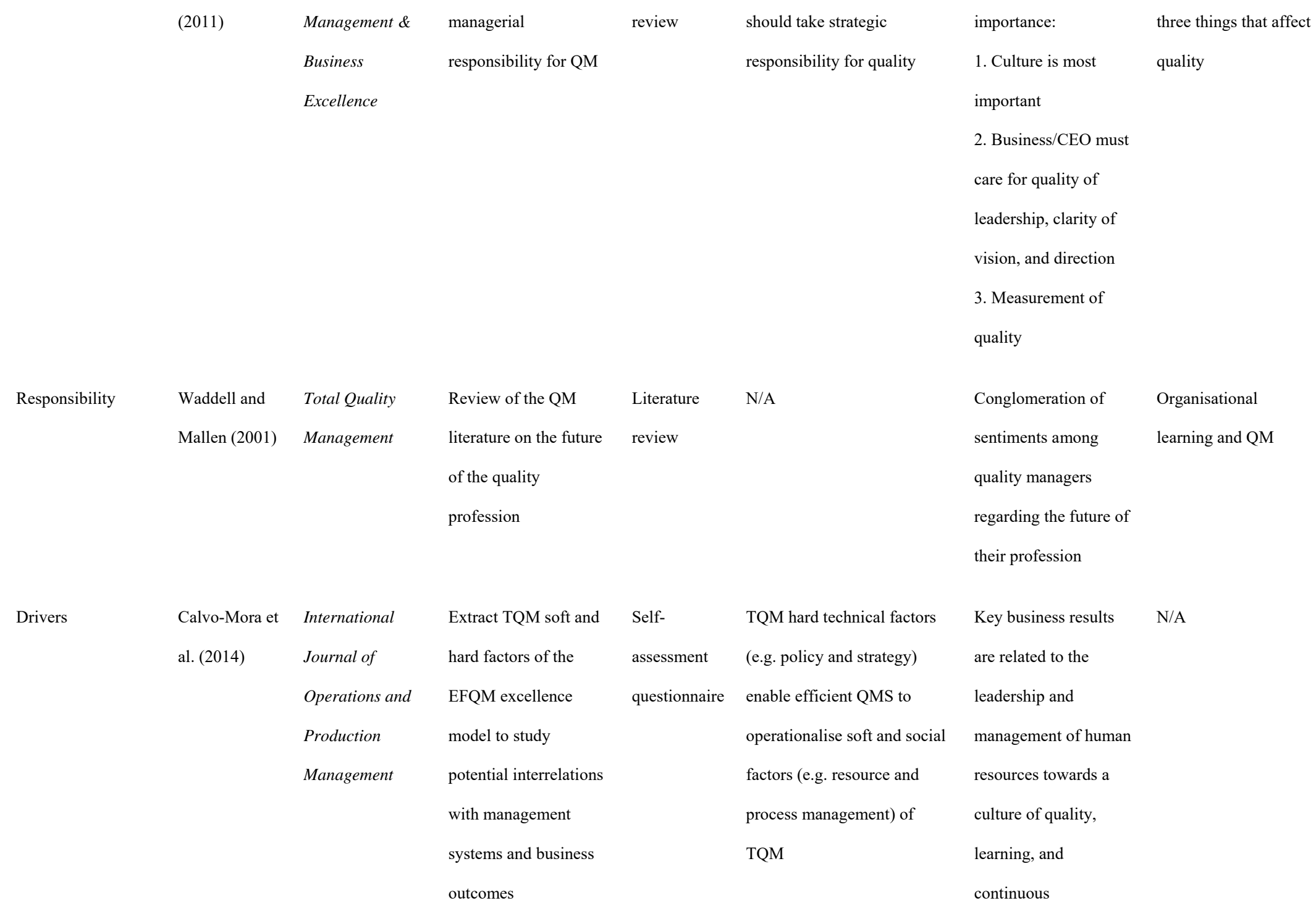


improvement

\begin{tabular}{|c|c|c|c|c|c|c|c|}
\hline \multirow[t]{2}{*}{ Drivers } & $\begin{array}{l}\text { Hietschold et } \\
\text { al. (2014) }\end{array}$ & $\begin{array}{l}\text { International } \\
\text { Journal of }\end{array}$ & $\begin{array}{l}\text { Propose a framework } \\
\text { that organisations can }\end{array}$ & $\begin{array}{l}\text { Literature } \\
\text { review, }\end{array}$ & $\begin{array}{l}\text { The structure of the complex } \\
\text { research field that measures }\end{array}$ & $\begin{array}{l}\text { Three-level framework } \\
\text { classified into } 11\end{array}$ & $\begin{array}{l}\text { Soft aspects of TQM } \\
\text { and how they affect }\end{array}$ \\
\hline & & $\begin{array}{l}\text { Production } \\
\text { Research }\end{array}$ & $\begin{array}{l}\text { use to measure critical } \\
\text { success factors } \\
\text { including TQM }\end{array}$ & $\begin{array}{l}\text { survey, and } \\
\text { focus groups }\end{array}$ & $\begin{array}{l}\text { the critical success factors } \\
\text { associated with implementing } \\
\text { TQM that are linked with } \\
\text { performance indicators }\end{array}$ & $\begin{array}{l}\text { dimensions and a } \\
\text { holistic set of } \\
\text { measurement } \\
\text { instruments to measure } \\
\text { each dimension }\end{array}$ & firm performance \\
\hline Drivers & $\begin{array}{l}\text { Lagrosen and } \\
\text { Lagrosen } \\
(2005)\end{array}$ & $\begin{array}{l}\text { International } \\
\text { Journal of } \\
\text { Operations \& } \\
\text { Production } \\
\text { Management }\end{array}$ & $\begin{array}{l}\text { Identify differences in } \\
\text { managers' perceptions } \\
\text { of the positive effects } \\
\text { of implementing TQM } \\
\text { produced by different } \\
\text { QM models and tools }\end{array}$ & Survey & $\begin{array}{l}\text { Correlations between the } \\
\text { adoption of TQM values and } \\
\text { successful QM; findings } \\
\text { indicate the usefulness of the } \\
\text { Swedish Quality Award, the } \\
\text { European Quality Award, and } \\
\text { ISO } 9000\end{array}$ & $\begin{array}{l}\text { Importance of } \\
\text { emphasising values for } \\
\text { successful QM }\end{array}$ & $\begin{array}{l}\text { Different effects of } \\
\text { QM practices and } \\
\text { significance of values }\end{array}$ \\
\hline
\end{tabular}


First, the results of the literature review revealed that the quality manager's responsibilities are central to the process of transferring the ownership of quality from quality professionals to managers. Camison and de las Peñas (2010) demonstrated that CEOs and quality managers perceive responsibilities related to quality differently. Quality managers have difficulty implementing QM in organisations, and should be adaptable to new roles and positions. Eriksson et al. (2016) suggested that one of the most important challenges is making QM a strategic issue for company owners to enable a longer-term strategic role for quality managers. Elg et al. (2011) found that quality managers' operational responsibilities are mostly concerned with meeting quality standards. Despite the consistency in their perceptions related to job responsibilities, quality managers have different views about the future of the QM profession (Waddell and Mallen, 2001). They are more concerned with maintaining quality standards than promoting dynamism and innovation dynamics (Burcher et al., 2008). Bayo-Moriones and Merino-Diaz de Cerio (2003) found that quality departments are often located near the top of organisational hierarchies in medium-sized or multinational companies, but are given less influence in smaller companies. Finally, Oakland (2011) described how CEO leadership (and an emphasis on quality) could foster a QM culture in an organisation.

Second, Calvo-Mora et al. (2014) investigated the influence of soft and hard TQM factors (i.e. drivers) on business results, finding that TQM strategies and policies can improve QM efficiency. The implementation of QM systems would thus be more likely to succeed if management measure strategic performance, and link QM systems with business outcomes. To measure the performance of QM implementation, Hietschold et al. (2014) suggested a three-level framework with 11 dimensions that imply that the responsibility for quality rests with the organisation's management team rather than just the quality department. Lagrosen 
and Lagrosen (2005) similarly identified differences in managers' perceptions of the effects of how different QM models and tools lead to the implementation of QM. Their research established positive correlations between the adoption of values in QM and its successful implementation.

\section{Discussion}

We analysed how contemporary QM research addresses three themes of the challenges experienced by practitioners to bridge the potential relevance gaps. Unfortunately, we could not find research addressing one of the three main themes - making quality a strategic concern for business owners. Although Alänge and Steiber (2009) discussed the role of the board of directors in sustaining major organisational change, research in this area is lacking, perhaps because owners are inaccessible to quality professionals. Nevertheless, studies of how owners can gain the ownership of quality are sought after by professionals. As such, this represents a potential relevance gap that future QM research should address, and we offer the following proposition:

Proposition I. Future empirical research should focus on how to make QM a strategic concern for owners.

Our second proposition relates to the identified challenge of making organisations agile and adaptable to changes in their business environments. Table 4 shows that this challenge has been addressed extensively. However, only eight of the 19 articles that tackle this challenge are empirically based. Further, many of the identified studies have also called for an empirical enquiry (e.g. Asif et al., 2013; Benner and Tushman, 2003). We therefore propose: 
Proposition II. Future research should feature empirical studies of QM's ambidexterity and adaptability.

Of the three research articles that highlight contextual dependencies, only Zhang et al. (2012) was empirical. The authors also indicated a need to identify other key contingency variables. Furthermore, Temponi (2006) addressed the need for more QM research based on specific business situations. Sheremata (2000) proposed a model that focusses on agility and changes in the business environment, specifically meant for rapid product development under time pressure. The variability of these studies demonstrates that effective QM is adapted to the context in which it is implemented. Given this, we propose that:

Proposition III. Future research should investigate how different contexts influence the outcomes associated with QM implementation.

Six articles indicated that QM research has paid too little attention to learning and innovation. In a review of learning and innovation, Adler (1999) argued for increased attention to strategies for specific organisational design types to facilitate employee involvement. The author also proposed theories on culture building through autocratic, organic, enabling bureaucratic, or coercive bureaucratic means. Steiber and Alänge (2013) similarly argued for a greater need to trust employees not only as problem-solvers, but also as innovators and knowledgeable decision-makers. Consistent with this logic, Kim et al. (2012) highlighted the need for further investigation into how and why certain QM practices yield innovation. Dervitsiotis (1998) and Kaynak (2003) established relationships between TQM principles and firm profitability. Finally, Choo et al. (2007) argued for more studies of the critical causal 
relationships between QM and various outcome measures related to learning and knowledge creation. We therefore offer the following proposition:

Proposition IV. Future research should focus on how QM can enhance organisational learning and innovation.

Bayo-Moriones and Merino-Diaz de Cerio (2003) argued that research on the impact of QM departments concerning how to implement QM in organisations is lacking. This assertion is consistent with Oakland (2011), who proposed that managers at various levels of an organisation should take strategic responsibility for quality. Delegating responsibility for quality to managers at all organisational levels may make quality managers uncertain about the future of their profession (Bayo-Moriones and Merino-Diaz de Cerio, 2003; Waddell and Mallen, 2001). In this vein, quality managers should be adaptable to new roles (Camison and de las Peñas, 2010) and capable of enhancing innovative capability in organisations, rather than maintaining the status quo (Burcher et al., 2008). This focus on transferring responsibility for quality within organisations leads us to propose:

Proposition V. Future research should explore how top managers can adopt responsibility and accountability for QM within their organisations.

Our final proposition concerns the drivers of successful QM initiatives. Lagrosen and Lagrosen (2005) and Hietschold et al. (2014) suggested the need for more research on how to explore the effects of QM practices and importance of its underlying values. Further, CalvoMora et al. (2014) showed that a QM culture built on leadership and effective human resource management could affect key outcomes. These studies suggest that further 
investigation into the role of values that underlie QM would be beneficial. Although managers have applied QM tools for many years, the role of QM principal values and how they affect those tools remains understudied. As such, we offer a final proposition:

Proposition VI. Future research should explore how QM principal values could be better integrated into organisations.

In sum, this study aimed to (a) identify the themes of the challenges perceived by QM practitioners and (b) better understand how these challenges are addressed by existing QM research to direct future scholars to bridge the relevance gaps between research and practice, thereby building on previous work in this area (see Carter, 2008; de-Margerie and Jiang, 2011; Hodgkinson and Rousseau, 2009; Huff, 2000a, 2000b; Starkey and Madan, 2001; Walsh et al., 2007). Our study showed the urgent need to address specific QM-related issues regarding the relevance gaps between research and practice. The six propositions listed above not only indicate specific areas that require more research, but also demonstrate the critical need for new approaches to narrow the relevance gap between QM research and practical challenges.

\section{Conclusions}

Our research resulted in three distinct overarching themes of QM challenges. The first theme relates to making organisations adaptable to changing environments. The second is about making quality a strategic concern for owners. The third deals with transferring the ownership of quality from quality professionals to managers. Based on these themes, an indepth literature review illustrates the state of QM research in relation to current challenges in 
practice. The extant literature shows five distinct areas of research: Ambidexterity, Contextualisation, Learning and Innovation, Responsibility, and Drivers. Based on the themes and five areas of research, six propositions for future research geared towards narrowing the potential relevance gaps were proposed.

First, future empirical research should focus on how to make QM a strategic concern for owners. Second, researchers should explore how QM can contribute to organisational ambidexterity and adaptability. Third, future research should determine how context influences how QM is applied. Fourth, researchers should investigate how QM can improve organisational learning and innovation. Fifth, future research should indicate how top managers can adopt the responsibilities of quality managers. Sixth, researchers should explore how the principal values of QM can be better integrated into organisations.

Consistent with contemporary management research, our analysis also indicates that new approaches to researching QM are necessary to limit the gaps between QM research and practice. Finally, our study suggests that QM research is dependent on adjacent areas of research, rather than being an area of research unto itself.

Finally, there are a number of key limitations to the research design to be stated. Although several of the studied organisations operate globally, we considered only organisations from a single geographical region. Still, the study shows similar results compared with the Delphi study conducted by the American Society for Quality (ASQ, 2013). Future research would, however, benefit from evaluating organisations from other geographic regions, as well, and also from considering a research design with practitioners to generate significant future QM challenges already in the initial start of the study. In terms of the quantitative analysis, to avoid rendering all variables as those with equal value regardless of ranking, the quantitative 
analysis used the covariance matrix. The results are also limited by the choice of employing a three-step systematic literature review method. In that choice of method, our review only contains studies from journals with more than one article matching the search criteria. The idea behind this limitation is that our research aimed for specific discourses of research themes; hence, a single journal publication is insufficient to show a distinct research discourse.

\section{Acknowledgements}

We are grateful to both reviewers and the editor for their constructive feedback that made us improve our article. The authors would also like to acknowledge Editage for proof-reading our manuscript.

This research is part of an initiative of the Swedish Quality Management Academy, a national industry/academy network for research on QM, chaired by the Swedish Institute for Quality. It is also part of the initiative for Excellence in Production Research (XPRES), which is a joint project between Mälardalen University, the Royal Institute of Technology, and Swerea IVF. XPRES is one of two Swedish government-funded strategic initiatives for research excellence in production engineering.

\section{References}

Abernathy, W.J., 1978. The productivity dilemma roadblock to innovation in the automobile industry. Baltimore: Johns Hopkins University Press.

Adler, P.S., 1999. Building better bureaucracies. Academy of Management Executive, 13, 36-47. 
Alänge, S., Steiber, A., 2009. The board's role in sustaining major organizational change: An empirical analysis of three change programs. International Journal of Quality and Service Sciences, 1, 280-93.

Asif, M, de Vries, H.J., 2015. Creating ambidexterity through quality management. Total Quality Management \& Business Excellence, 26, 1226-41.

Asif, M., de Vries, H., Ahmad, N., 2013. Knowledge creation through quality management. Total Quality Management \& Business Excellence, 24, 664-77.

ASQ (American Society for Quality) 2013. The 2013 ASQ global state of quality research. Milwaukee, WI: American Society for Quality.

Backström, T., Fundin, A., Johansson, P.E., 2017. Innovative quality improvements in operations: introducing emergent quality management. USA: Springer International Publishing.

Benner, M.J., Tushman, M.L., 2003. Exploitation, exploration, and process management: The productivity dilemma revisited. Academy of Management Review, 28, 238-56.

Benner, M.J., Tushman, M.L. 2015. Reflections on the 2013 decade award - exploitation, exploration, and process management: The productivity dilemma revisited. Academy of Management Review, 40, 497-514.

Bayo-Moriones, A., Merino-Diaz de Cerio, J., 2003. The status of quality departments: Empirical evidence for the Spanish manufacturing industry. International Journal of Quality \& Reliability Management, 20, 569-84.

Behmer, F., Jochem, R., Hanke, H., 2016. Planning and reorganising quality management organisations: An empirical analysis of current practise. Total Quality Management \& Business Excellence, 27, 96378. 
Burcher, P.G., Lee, G.L., Waddell, D., 2008. The challenges for quality managers in Britain and Australia. The TQM Journal, 20, 45-58.

Browne, M.W., 1968. A comparison of factor analytic techniques. Psychometrika, 33, 267-334.

Calvo-Mora, A., Ruiz-Moreno, C., Picón-Berjoyo, A., Cauzo-Bottala, L., 2014. Mediation effect of TQM technical factors in excellence management systems. Journal of Business Research, 67, 769-74.

Camison, C., de las Peñas, J.P., 2010. The future of the quality/excellence function: A vision from the Spanish firm. Total Quality Management, 21, 649-72.

Carter, C.R., 2008. Knowledge production and knowledge transfer: Closing the research-practice gap. Journal of Supply Chain Management, 44, 78-82.

Cattell, R.B., 1966. The scree test for the number of factors. Multivariate Behavioral Research, 1, 245-76.

Chen, X.Y., 2008. Applying total quality management in academic libraries, in Proceedings of the $5^{\text {th }}$ International Conference of Innovation Management, Entrepreneurship, and Sustainability, Vol. I and II. University of Economics, Prague, Czech Republic, pp. 3201-05.

Choo, A.S., Linderman, K.W., Schroeder, R.G., 2007. Method and psychological effects on learning behaviors and knowledge creation in quality improvement projects. Management Science, 53, 437-50.

Comrey, A.L., 1978. Common methodological problems in factor analytic studies. Journal of Consulting and Clinical Psychology, 46, 648-9.

Comrey, A.L., Lee, H.B., 1992. A first course in factor analysis, second ed. Hillsdale, NJ: Lawrence Earlbaum Associates. 
Dean, J.W., Bowen, D.E., 1994. Management theory and total quality: Improving research and practice through theory development. Academy of Management Review, 19, 392-418.

De-Margerie, V., Jiang, B., 2011. How relevant is OM research to managerial practice? An empirical study of top executives’ perceptions. International Journal of Operations \& Production Management, 31, 124-47.

Douglas, T.J., 2001. Total quality management implementation and competitive advantage: The role of structural control and exploration. Academy of Management Journal, 44, 158-69.

Dervitsiotis, K.N., 1998. The challenge of managing organizational change: Exploring the relationship of reengineering, developing learning organizations and total quality management. Total Quality Management, 9, 109-22.

Elg, M., Gremyr, I., Hellström, A., Witell, L., 2011. The role of quality managers in contemporary organisations. Total Quality Management \& Business Excellence, 22, 795-806.

El Ouardighi, F., 2014. Supply quality management with optimal wholesale price and revenue sharing contracts: A two-stage game approach. International Journal of Production Economics, 156, 260-8.

Eriksson, H., Gremyr, I., Bergquist, B., Garvare, R., Fundin, A., Wiklund, H., Whester, M., Sörqvist, L. 2016. Exploring quality challenges and the validity of excellence models. International Journal of Operations \& Production Management, 36, 1201-21.

Fernández Cruz, F.J., Egido Gálvez, I., Carballo Santaolalla, R., 2016. Impact of quality management systems on teaching-learning processes. Quality Assurance in Education, 24, 394-415.

Fundin, A., Bergman, B., Elg, M. 2017. The quality dilemma: Combining development and stability. In: Backström, T., Fundin, A., Johansson, P.E., (Eds.). Innovative quality improvements in operations: introducing emergent quality management. USA: Springer International Publishing, 9-33. 
Giroux, H., 2006. 'It was such a handy term': Management fashions and pragmatic ambiguity. Journal of Management Studies, 43, 1227-60.

Glaser, B., Strauss, A., 1967. The discovery of grounded theory: Strategies for qualitative research. USA: Adeline.

Gorsuch, R.L., 1973. Using Bartlett's significance test to determine the number of factors to extract. Educational and Psychological Measurement, 33, 361-4.

Gorsuch, R.L., 1974. Factor analysis. Philadelphia, PA: WB Saunders Co.

Grosse, E.H., Glock, C.G., Müller, S. 2015. Production economics and the learning curve: A meta-analysis. International Journal of Production Economics, 170, 401-12.

Gupta, A.K., Smith, K., Shalley, C.E., 2006. The interplay between exploration and exploitation. Academy of Management Journal, 49, 693-706.

Guler, I., Guillén, M.F., Macpherson, J.M., 2002. Global competition, institutions, and the diffusion of organizational practices: The international spread of ISO 9000 quality certificates. Administrative Science Quarterly, 47, 207-32.

Guttman, L., 1954. Some necessary conditions for common factor analysis. Psychometrika, 19, 149-61.

Harris, R., McAdam, R., McCausland, I., Reid, R., 2013. Levels of innovation within SMEs in peripheral regions: The role of business improvement initiatives. Journal of Small Business and Enterprise Development, 20, 102-24.

Haffar, M., Al-Karaghouli, W., Irani, Z., Djebarni, R., Gbadamosi, G., 2016. The influence of individual readiness for change dimensions on quality management implementation in Algerian manufacturing 
organisations. International Journal of Production Economics.

https://doi.org/10.1016/j.ijpe.2016.08.024.

Heras-Saizarbitoria, I., Boiral, O., 2013. ISO 9001 and ISO 14001: Towards a research agenda on management system standards. International Journal of Management Reviews, 15, 47-65.

Hietschold, N., Reinhardt, R., Gurtner, S., 2014. Measuring critical success factors of TQM implementation successfully: A systematic literature review. International Journal of Operations \& Production Management, 52, 6254-72.

Hochrein, S., Glock, C.H., 2012. Systematic literature reviews in purchasing and supply management research: A tertiary study. International Journal of Integrated Supply Management, 7, 215-45.

Hochrein, S., Glock, C.H., Bogaschewsky, R., Heider, M., 2015. Literature reviews in supply chain management: A tertiary study. Management Review Quarterly, 65, 239-80.

Hodgkinson, G.P., Rousseau, D.M., 2009. Bridging the rigour-relevance gap in management research: It's already happening! Journal of Management Studies, 46, 534-46.

Hoerl, R.W., Snee, R., 2010. Statistical thinking and methods in quality improvement: A look to the future. Quality Engineering 22, 119-129.

Hsu, S.-H., Tzeng, S.-F., Wang, Y.-C., 2007. How to increase exploration within the TQM practice. Total Quality Management \& Business Excellence, 18, 1075-81.

Huff, A.S., 2000a., 1999 Presidential address: Changes in organizational knowledge production. Academy of Management Review, 25, 288-93.

Huff, A.S., 2000b. Citigroup's John Reed and Stanford's James March on management research and practice. Academy of Management Executive, 14, 52-64. 
Institute for Digital Research and Education, University of California, 2016. Annotated SPSS Output, Factor Analysis. http://www.ats.ucla.edu/stat/spss/output/factor1.htm.

Jackson, S. A., Gopalakrishna-Remani, V., Mishra, R., Napier, R., 2016. Examining the impact of design for environment and the mediating effect of quality management innovation on firm performance. International Journal of Production Economics, 173, 142-52.

Johnson, R.A., Wichern, D.W., 1992. Applied multivariate statistical analysis, third edition. Englewood Cliffs, NJ: Prentice Hall.

Kaiser, H.F., 1974. An index of factorial simplicity, Psychometrika, 39, 31-6.

Kaynak, H., 2003. The relationship between total quality management practices and their effects on firm performance. Journal of Operations Management, 21, 405-35.

Keeney, S., 2010. The Delphi technique. In: Gerrish, K., Lacey, A. (Eds.). The research process in nursing. London: Blackwell Publishing, 227-236.

Kieser, A., Leiner, L., 2009. Why the rigour-relevance gap in management research is unbridgeable. Journal of Management Studies, 46, 516-33.

Klefsjö, B., Bergquist, B., Garvare, R., 2008. Quality management and business excellence, customers and stakeholders: Do we agree on what we are talking about, and does it matter? The TQM Journal, 20, $120-9$.

Kim, D.Y., Kumar, V., Kumar, U., 2012. Relationship between quality management practices and innovation. Journal of Operations Management, 30, 295-315. 
Lagrosen, Y., Lagrosen, S., 2005. The effects of quality management: A survey of Swedish quality professionals. International Journal of Operations \& Production Management, 25, 940-52.

Levinthal, D.A., March, J.G., 1993. The myopia of learning. Strategic Management Journal, 14, 95-112.

McAdam, R., Miller, K., McSorley, C., 2016. Towards a contingency theory perspective of quality management in enabling strategic alignment. International Journal of Production Economics. https://doi.org/10.1016/j.ijpe.2016.07.003.

McAdam, R., Reid, R., Shevlin, M., 2014. Determinants for innovation implementation at SME and inter SME levels within peripheral regions. International Journal of Entrepreneurial Behavior \& Research, 20, $66-90$.

Mote, T.A., 1970. An artifact of the rotation of too few factors: Study orientation vs. trait anxiety. Revista Interamericana de Psicologia/Interamerican Journal of Psychology, 4, 171-3.

Moreno-Luzon, M.D., Gil-Marques, M., Arteaga, F., 2014. Driving organisational ambidexterity through process management: The key role of cultural change. Total Quality Management \& Business Excellence, 25, 1026-38.

Moreno-Luzon, M.D., Valls Pasola, J., 2011. Ambidexterity and total quality management: Towards a research agenda. Management Decision, 49, 927-47.

Michaels, S.E., 1964. The usefulness of experimental designs. Journal of the Royal Statistical Society. Series C (Applied Statistics), 13, 221-35.

Morrison, S.J., 1957. The study of variability in engineering design. Applied Statistics, 6, 133-38.

Nilsson-Witell, L., Fundin, A., 2005. Dynamics of service attributes: A test of Kano's theory of attractive quality. International Journal of Service Industry Management, 16, 152-68. 
Oakland, J., 2011. Leadership and policy deployment: The backbone of TQM. Total Quality Management \& Business Excellence, 22, 517-34.

O’Neill, P., Sohal, A., Teng, C.W., 2016. Quality management approaches and their impact on firms' financial performance: An Australian study. International Journal of Production Economics, 171, 381-93.

Parast, M.M., Adams, S.G., 2012. Corporate social responsibility, benchmarking, and organizational performance in the petroleum industry: A quality management perspective. International Journal of Production Economics, 139, 447-58.

Phan, A.C., Abdallah, A.B., Matsui, Y., 2011. Quality management practices and competitive performance: Empirical evidence from Japanese manufacturing companies. International Journal of Production Economics, 133, 518-29.

Pinho, J.C., 2008. TQM and performance in small medium enterprises: The mediating effect of customer orientation and innovation, International Journal of Quality \& Reliability Management, 25, 256-75.

Rescher, N., 1998. Predicting the future: An introduction to the theory of forecasting. Albany, NY: State University of New York Press.

Rhoades, E.A., 2011. Literature reviews. Volta Review, 111, 353-68.

Shewhart, W.A., 1931. Economic control of quality of manufactured product. New York: D. Van Nostrand Company.

Shewhart, W.A., 1939. Statistical method from the viewpoint of quality control. Washington, D.C.: Graduate School of the Department of Agriculture. 
Sheremata, W.A., 2000. Centrifugal and centripetal forces in radical new product development under time pressure. Academy of Management Review, 25, 389-408.

Sitkin, S.B., Sutcliffe, K.M., Schroeder, R.G., 1994. Distinguishing control from learning in total quality management: A contingency perspective. Academy of Management Review, 19, 537-64.

Sousa, R., Voss, C.A., 2002. Quality management revisited: A reflective review and agenda for the future. Journal of Operations Management, 20, 91-109.

Starkey, K., Madan, P., 2001. Bridging the relevance gap: Aligning stakeholders in the future of management research. British Journal of Management, 12, 3-26.

Steiber, A., Alänge, S., 2013. Do TQM principles need to change? Learning from a comparison to Google Inc. Total Quality Management \& Business Excellence, 24, 48-61.

Taguchi, G., Wu, Y., 1979. Introduction to off-line quality control. Meieki Nakamura-Ku Magaya, Japan: Central Japan Quality Control Association.

Talib, F., Rahman, Z., Azam, M., 2011. Best practices of total quality management implementation in health care settings. Health Marketing Quarterly, 28, 232-52.

Temponi, C., 2006. Scalable enterprise systems: Quality management issues. International Journal of Production Economics, 99, 222-35.

Tranfield, D., Denyer, D., Smart, P., 2003. Towards a methodology for developing evidence-informed management knowledge by means of systematic review. British Journal of Management, 14, 20722.

Tushman, M.L., O’Reilly, C.A., 1996. The ambidextrous organizations: Managing evolutionary and revolutionary change. California Management Review, 38, 8-30. 
Van Rossum, L., Aij, K.H., Simons, F.E., van der Eng, N., ten Have, W.D., 2016. Lean healthcare from a change management perspective: The role of leadership and workforce flexibility in an operating theatre. Journal of Health Organization and Management, 30, 475-93.

Wachter, K.W., 1976. Probability plotting points for principal components. In: Hoagline, D., Welsch, R. (Eds.). Ninth interface symposium on computer science and statistics. Boston, MA: Rindle, Weber, \& Schmidt, 299-308.

Waddell, D., Mallen, D., 2001. Quality managers: Beyond 2000? Total Quality Management, 12, 373-84.

Walsh, J.P., Tushman, M.L., Kimberly, J.R., Starbuck, B., Ashford, S., 2007. On the relationship between research and practice debate and reflections. Journal of Management Inquiry, 16, 128-54.

Wiengarten, F., Pagell, M., 2012. The importance of quality management for the success of environmental management initiatives. International Journal of Production Economics, 140, 407-15.

Wu, S. J., Zhang, D., 2013. Analyzing the effectiveness of quality management practices in China. International Journal of Production Economics, 144, 281-89.

Yeung, A.C., Cheng, T.E., Chan, L.Y., 2004. From customer orientation to customer satisfaction: The gap between theory and practice. IEEE Transactions on Engineering Management, 51, 85-97.

Zhang, D., Linderman, K., Schroeder, R.G., 2012. The moderating role of contextual factors on quality management practices. Journal of Operations Management, 30, 12-23.

Zeng, J., Phan, C. A., Matsui, Y., 2015. The impact of hard and soft quality management on quality and innovation performance: An empirical study. International Journal of Production Economics, 162, 216-26. 
Zeng, J., Zhang, W., Matsui, Y., Zhao, X., 2017. The impact of organizational context on hard and soft quality management and innovation performance. International Journal of Production Economics, 185, 240-51. 


\section{Appendix}

Table A1. Initial model tests

KMO and Bartlett's Test ${ }^{a}$

KMO Measure of Sampling Adequacy.

.486

Bartlett's Test

Approx. Chi-Square

40.222

$\mathrm{df}$

45

p-value

.674

${ }^{\mathrm{a} B a s e d}$ on correlation 


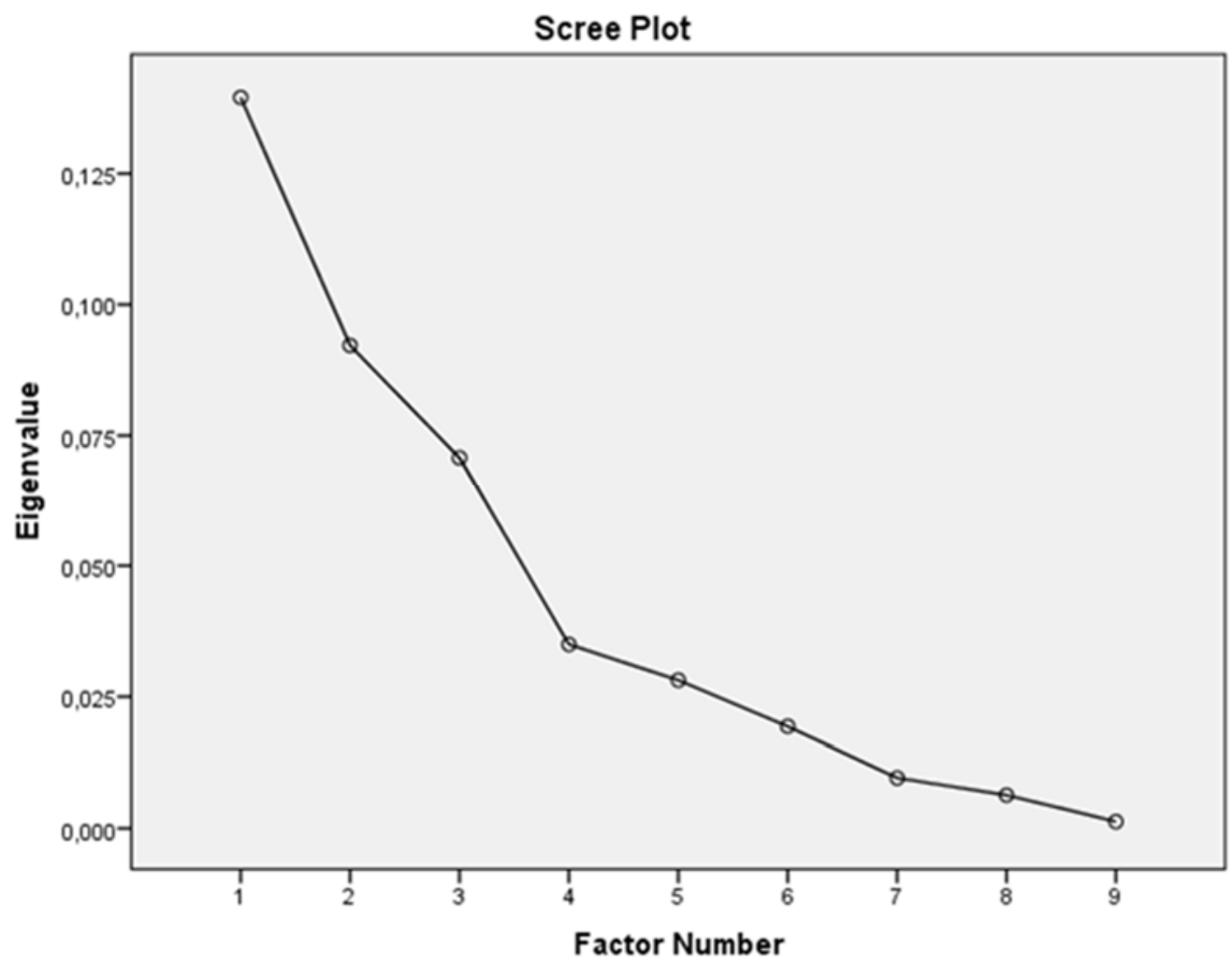

Figure A1. Scree plot of the reduced factor model. 
Table A2. Extraction properties of the final model.

\section{Total Variance Explained}

\begin{tabular}{|c|c|c|c|c|c|c|c|}
\hline & \multirow[b]{2}{*}{ Factor } & \multicolumn{3}{|c|}{ Initial Eigenvalues } & \multicolumn{3}{|c|}{ Extraction Sums of Squared Loadings } \\
\hline & & Total & $\begin{array}{l}\% \text { of } \\
\text { Variance }\end{array}$ & $\begin{array}{l}\text { Cumulative } \\
\%\end{array}$ & Total & $\begin{array}{l}\% \text { of } \\
\text { Variance }\end{array}$ & $\begin{array}{l}\text { Cumulative } \\
\%\end{array}$ \\
\hline & 1 & .140 & 34.695 & 34.695 & .079 & 19.687 & 19.687 \\
\hline & 2 & .092 & 22.927 & 57.622 & .024 & 5.993 & 25.680 \\
\hline & 3 & .071 & 17.589 & 75.211 & .015 & 3.684 & 29.363 \\
\hline & 4 & .035 & 8.694 & 83.904 & & & \\
\hline \multirow[t]{8}{*}{ Raw } & 5 & .028 & 6.996 & 90.900 & & & \\
\hline & 6 & .019 & 4.812 & 95.711 & & & \\
\hline & 7 & .010 & 2.389 & 98.101 & & & \\
\hline & 8 & .006 & 1.577 & 99.678 & & & \\
\hline & 9 & .001 & .322 & 100.000 & & & \\
\hline & 1 & .140 & 34.695 & 34.695 & .891 & 9.902 & 9.902 \\
\hline & 2 & .092 & 22.927 & 57.622 & 1.107 & 12.294 & 22.196 \\
\hline & 3 & .071 & 17.589 & 75.211 & .758 & 8.417 & 30.613 \\
\hline \multirow[t]{4}{*}{ Rescaled } & 4 & .035 & 8.694 & 83.904 & & & \\
\hline & 5 & .028 & 6.996 & 90.900 & & & \\
\hline & 6 & .019 & 4.812 & 95.711 & & & \\
\hline & 7 & .010 & 2.389 & 98.101 & & & \\
\hline
\end{tabular}


8 
Table A3. Final model Bartlett's and KMO tests ${ }^{\mathrm{a}}$

KMO Measure of Sampling Adequacy.

.520

Bartlett's Test

Approx. Chi-Square

121.103

$\mathrm{df}$

36

p-value

.000

${ }^{\mathrm{a} B a s e d}$ on correlations 
Table A4. Extraction properties of the final model ${ }^{\mathrm{a}}$

\section{Communalities}

\begin{tabular}{|c|c|c|c|c|}
\hline & \multicolumn{2}{|l|}{ Raw } & \multicolumn{2}{|c|}{ Rescaled } \\
\hline & Initial & Extraction & Initial & Extraction \\
\hline Create flexible processes that & $2.554 \mathrm{E}-5$ & .005 & .003 & .530 \\
\hline \multicolumn{5}{|l|}{ support innovation } \\
\hline Develop an organisational & .000 & .013 & .008 & .434 \\
\hline \multicolumn{5}{|l|}{ innovation ability } \\
\hline Combine the need for & $1.129 \mathrm{E}-5$ & .002 & .001 & .143 \\
\hline \multicolumn{5}{|l|}{ standardisation with the need for } \\
\hline \multicolumn{5}{|l|}{ innovation } \\
\hline Make use of the ethnical and & $1.193 \mathrm{E}-6$ & .000 & .001 & .206 \\
\hline \multicolumn{5}{|l|}{ cultural diversity of staff members } \\
\hline Develop new forms of operations & .000 & .004 & .008 & .150 \\
\hline \multicolumn{5}{|l|}{ to comply with customers' needs } \\
\hline Use IT to improve the business & $7.740 \mathrm{E}-5$ & .011 & .003 & .426 \\
\hline Make the organisation agile and & .001 & .058 & .012 & .621 \\
\hline \multicolumn{5}{|l|}{ adaptable to rapid changes within } \\
\hline \multicolumn{5}{|l|}{ the business environment. } \\
\hline Transfer the ownership of quality & .001 & .013 & .009 & .130 \\
\hline \multicolumn{5}{|l|}{ from quality professions to } \\
\hline \multicolumn{5}{|l|}{ management } \\
\hline Make quality a strategic concern & .001 & .012 & .008 & .116 \\
\hline for owners & & & & \\
\hline
\end{tabular}

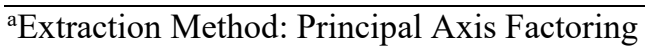

